\title{
Humidity-Induced Mechanical Behavior and Proton Transport Mechanism in Aromatic Multiblock Ionomer Membranes
}

Emilie Planes ${ }^{1, *}$, Huu-Dat Nguyen ${ }^{1, * *}$, Thi Khanh Ly Nguyen ${ }^{1}$, Nicolas Charvin ${ }^{1}$, Lionel Flandin $^{1}$, Sandrine Lyonnard ${ }^{2}$, Cristina Iojoiu ${ }^{1}$

${ }^{1}$ Univ. Grenoble Alpes, Univ. Savoie Mont Blanc, CNRS, Grenoble INP\#, LEPMI, UMR5279, 38000 Grenoble, France

${ }^{2}$ Univ. Grenoble Alpes, CEA, CNRS, IRIG, SyMMES, F-38054 Grenoble, France

*Correspondence to: Emilie.Planes@univ-smb.fr

**Current address: Laboratoire Matériaux Batteries (LM)/STB/DEHT/LITEN, CEA Grenoble, 17 avenue des Martyrs, 38000 Grenoble, France

\# Institute of Engineering and Management Univ. Grenoble Alpes

\section{Supporting Information}

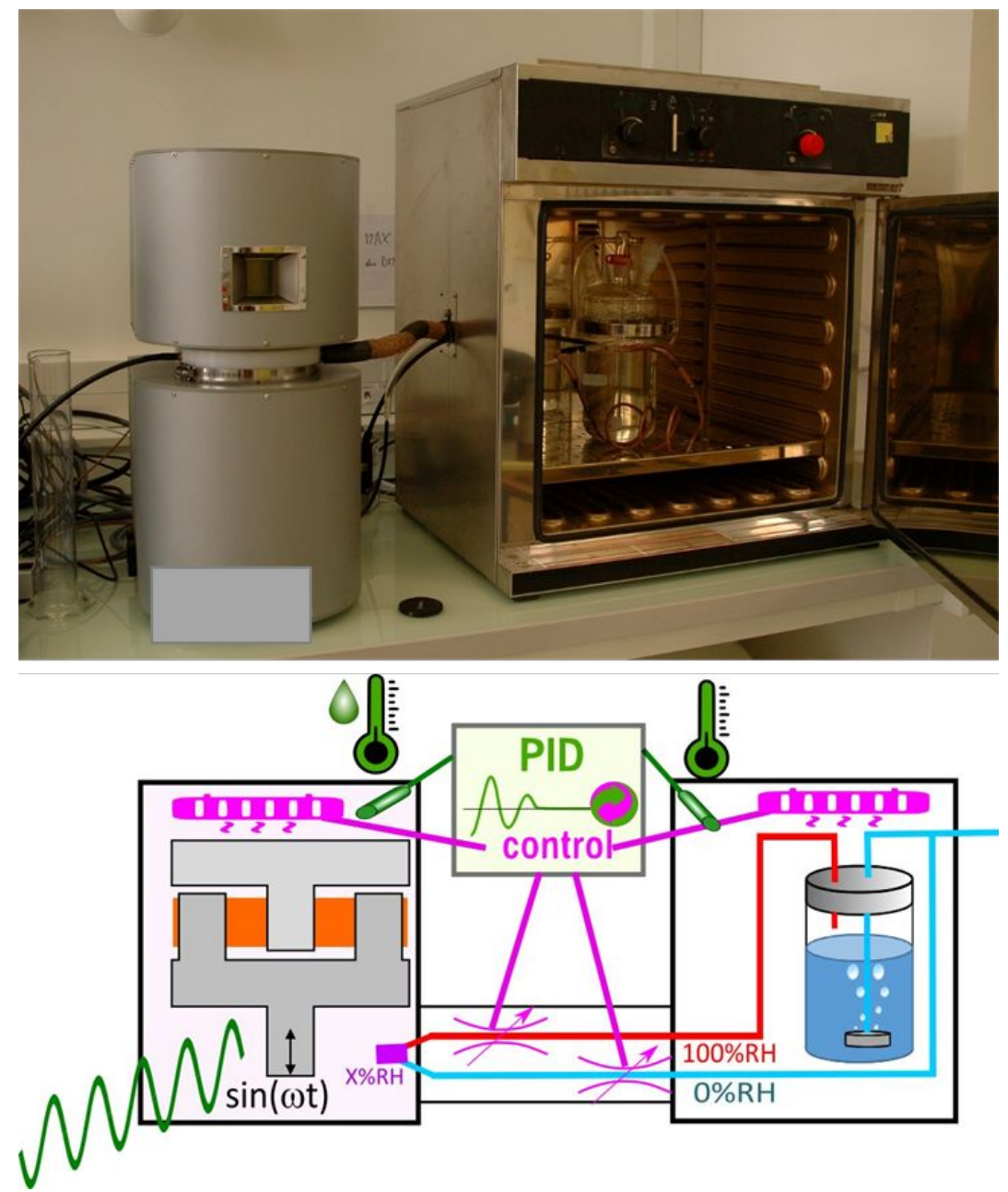

Figure S1. Schematic illustration of the setup used for DMA measurements in a temperatureand humidity-controlled conditions. 

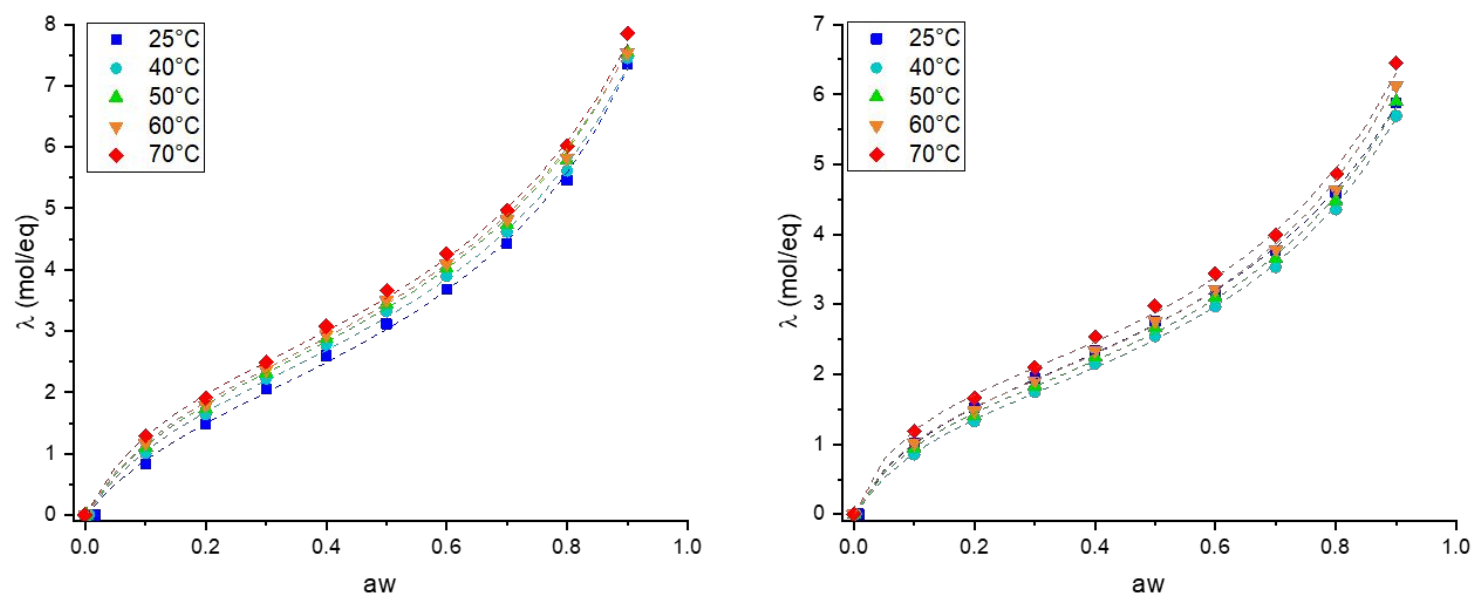

Figure S2. Water vapor sorption isotherm represented as hydration number $\lambda$ of Nafion (left) and IN1515 (right) at $25^{\circ} \mathrm{C}$ (blue squares), $40^{\circ} \mathrm{C}$ (turquoise diamonds), $50^{\circ} \mathrm{C}$ (green triangles), $60^{\circ} \mathrm{C}$ (orange triangles), $70^{\circ} \mathrm{C}$ (red diamonds) as a function of water activity $a_{w}$; these data are fitted with NDMS model represented with dotted lines.

Nafion

\begin{tabular}{|l|l|l|l|l|l|}
\hline Temperature $\left({ }^{\circ} \mathrm{C}\right)$ & 25 & 40 & 50 & 60 & 70 \\
\hline $\mathrm{K}$ & $0.78 \pm 0.02$ & $0.77 \pm 0.01$ & $0.77 \pm 0.01$ & $0.76 \pm 0.01$ & $0.76 \pm 0.01$ \\
\hline $\mathrm{C}$ & $2.08 \pm 0.12$ & $2.17 \pm 0.09$ & $2.24 \pm 0.07$ & $2.31 \pm 0.08$ & $2.33 \pm 0.09$ \\
\hline $\mathrm{A}$ & $6.78 \pm 1.19$ & $8.35 \pm 1.19$ & $9.07 \pm 1.00$ & $9.27 \pm 1.07$ & $10.83 \pm 1.48$ \\
\hline
\end{tabular}

IN1515

\begin{tabular}{|l|l|l|l|l|l|}
\hline Temperature $\left({ }^{\circ} \mathrm{C}\right)$ & 25 & 40 & 50 & 60 & 70 \\
\hline $\mathrm{K}$ & $0.76 \pm 0.01$ & $0.78 \pm 0.01$ & $0.78 \pm 0.01$ & $0.79 \pm 0.01$ & $0.78 \pm 0.01$ \\
\hline $\mathrm{C}$ & $1.92 \pm 0.06$ & $1.76 \pm 0.04$ & $1.80 \pm 0.05$ & $1.84 \pm 0.06$ & $1.93 \pm 0.07$ \\
\hline $\mathrm{A}$ & $11.55 \pm 1.38$ & $10.00 \pm 0.96$ & $11.43 \pm 1.29$ & $12.43 \pm 1.66$ & $15.97 \pm 2.9$ \\
\hline
\end{tabular}

Table S1. Extracted parameters of NDMS model: $C, k$ and $A$ for Nafion and IN1515 ionomers as a function of temperature.

\section{Analyticals models issued from literature to fit sorption data:}

BET model with 3 parameters ${ }^{1}$ :

$$
\lambda=\frac{a C_{p} a_{w} 1-(n+1) a_{w}{ }^{n}+n a_{w}{ }^{n+1}}{1-a_{w} 1+\left(C_{p}-1\right) a_{w}-C_{p} a_{w}{ }^{n+1}}
$$

Henry model with one parameter: 


$$
\lambda=K_{H} a_{w}
$$

NDMS model with three parameters ${ }^{2}$ :

$$
\lambda=C \frac{k \times a_{w}}{1-k \times a_{w}}+C \frac{(A-1) \times k \times a_{w}}{1+(A-1) \times k \times a_{w}}
$$

Park model with three parameters (Park3):

$$
\lambda=K_{H} a_{w}+B a_{w}^{n}
$$

Park model with five parameters $(\operatorname{Park} 5)^{2}$ :

$$
\lambda=\frac{A_{L} b_{L} a_{w}}{1+b_{L} a_{w}}+K_{H} a_{w}+n K_{H}^{n} K_{a} a_{w}{ }^{n}
$$

\begin{tabular}{|c|c|c|c|c|c|c|c|c|c|c|}
\hline & \multicolumn{5}{|c|}{ Nafion } & \multicolumn{5}{|c|}{ IN1515 } \\
\hline & $25^{\circ} \mathrm{C}$ & $40^{\circ} \mathrm{C}$ & $50^{\circ} \mathrm{C}$ & $60^{\circ} \mathrm{C}$ & $70^{\circ} \mathrm{C}$ & $25^{\circ} \mathrm{C}$ & $40^{\circ} \mathrm{C}$ & $50^{\circ} \mathrm{C}$ & $60^{\circ} \mathrm{C}$ & $70^{\circ} \mathrm{C}$ \\
\hline \multicolumn{11}{|l|}{ BET } \\
\hline$A$ & 1.6 & 1.7 & 1.7 & 1.8 & 1.8 & 1.4 & 1.3 & 1.3 & 1.4 & 1.5 \\
\hline $\mathrm{Cp}$ & 11.0 & 14.0 & 17.0 & 17.0 & 21.0 & 19.0 & 19.0 & 24.0 & 27.0 & 39.0 \\
\hline $\mathrm{n}$ & 9.5 & 9.0 & 8.8 & 8.5 & 8.6 & 8.3 & 9.2 & 9.1 & 9.2 & 8.9 \\
\hline \multicolumn{11}{|c|}{ Henry } \\
\hline $\mathrm{KH}$ & 7.0 & 7.2 & 7.4 & 7.5 & 7.8 & 5.9 & 5.6 & 5.8 & 6.0 & 6.4 \\
\hline \multicolumn{11}{|c|}{ PARK 3} \\
\hline $\mathrm{KH}$ & 6.3 & 6.8 & 7.0 & 7.1 & 7.4 & 5.6 & 5.2 & 5.4 & 5.6 & 6.0 \\
\hline$B$ & 6.7 & 8.4 & 7.8 & 9.8 & 14.0 & 6.8 & 5.3 & 7.3 & 8.5 & 33.0 \\
\hline $\mathrm{n}$ & 13.0 & 17.0 & 17.0 & 20.0 & 24.0 & 20.0 & 16.0 & 19.0 & 20.0 & 33.0 \\
\hline \multicolumn{11}{|c|}{ PARK 5} \\
\hline $\mathrm{AL}$ & 2.9 & 1.0 & 0.9 & 0.8 & 0.9 & 1.7 & 0.9 & 0.7 & 0.7 & 0.9 \\
\hline $\mathrm{bL}$ & 1.9 & 9.0 & 17.0 & 44.0 & 58.0 & 6.9 & 12.0 & 29.0 & 50.0 & 78.0 \\
\hline $\mathrm{KH}$ & 3.4 & 5.0 & 5.2 & 5.6 & 5.7 & 2.7 & 3.4 & 3.9 & 4.1 & 4.3 \\
\hline $\mathrm{Ka}$ & 0.7 & 0.6 & 0.6 & 0.5 & 0.6 & 0.6 & 0.5 & 0.5 & 0.5 & 0.5 \\
\hline $\mathrm{n}$ & 7.5 & 8.5 & 8.1 & 8.8 & 9.1 & 5.8 & 7.1 & 8.1 & 8.4 & 9.3 \\
\hline
\end{tabular}

The experimental data obtained for Nafion and $\mathrm{IN} 1515$ at $25^{\circ} \mathrm{C}, 40^{\circ} \mathrm{C}, 50^{\circ} \mathrm{C}, 60^{\circ} \mathrm{C}$ and $70^{\circ} \mathrm{C}$ were fitted with these models. The results are presented in Figures S3 and S4 and in Table 2.

Table 2. Extracted parameters of BET, Henry and Park models for Nafion and IN1515 ionomers as a function of temperature 

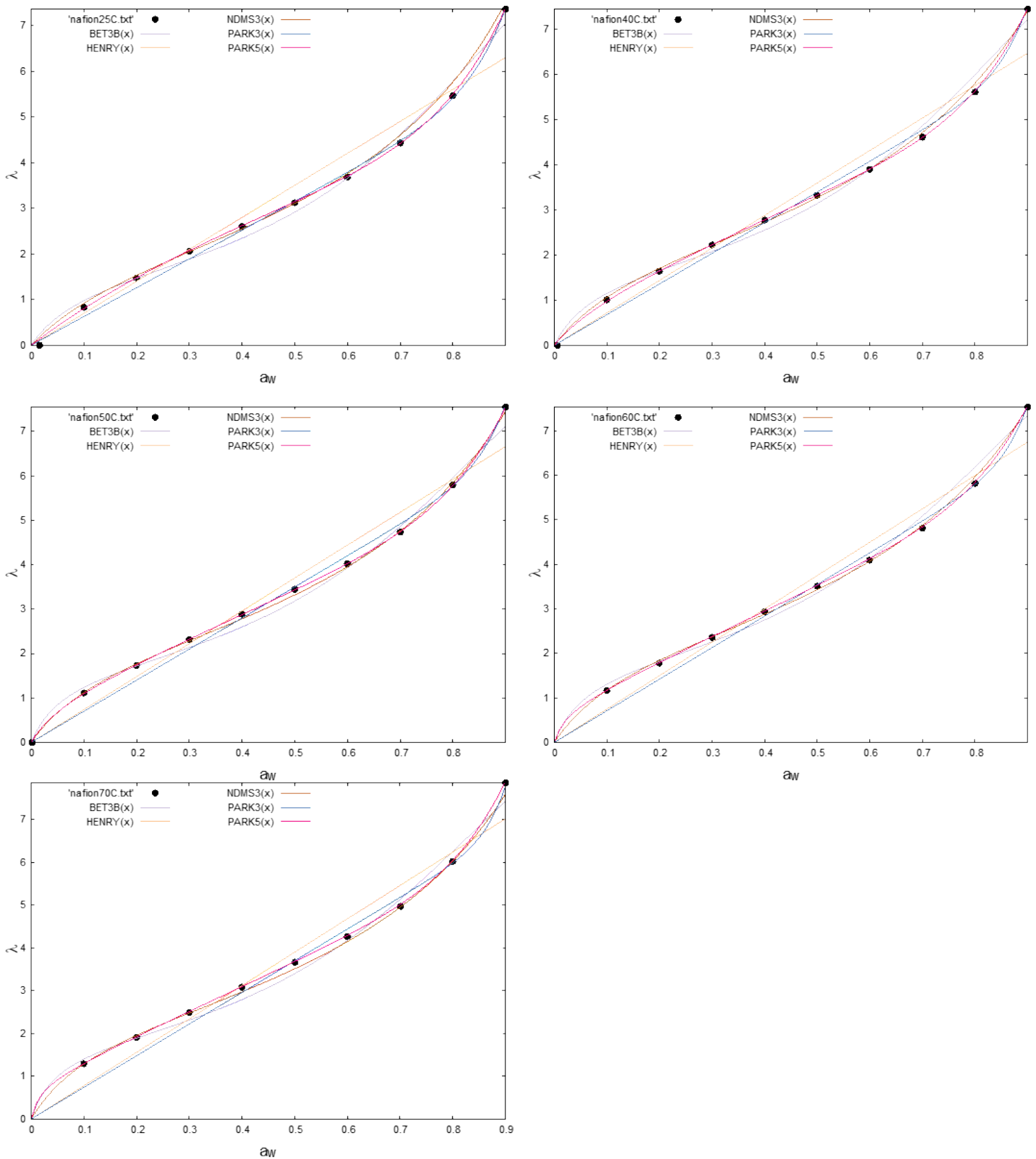

aw

Figure S3. Fits of the sorption data with different models issued from literature for Nafion at $25^{\circ} \mathrm{C}, 40^{\circ} \mathrm{C}, 50^{\circ} \mathrm{C}, 60^{\circ} \mathrm{C}$ and $70^{\circ} \mathrm{C}$ 

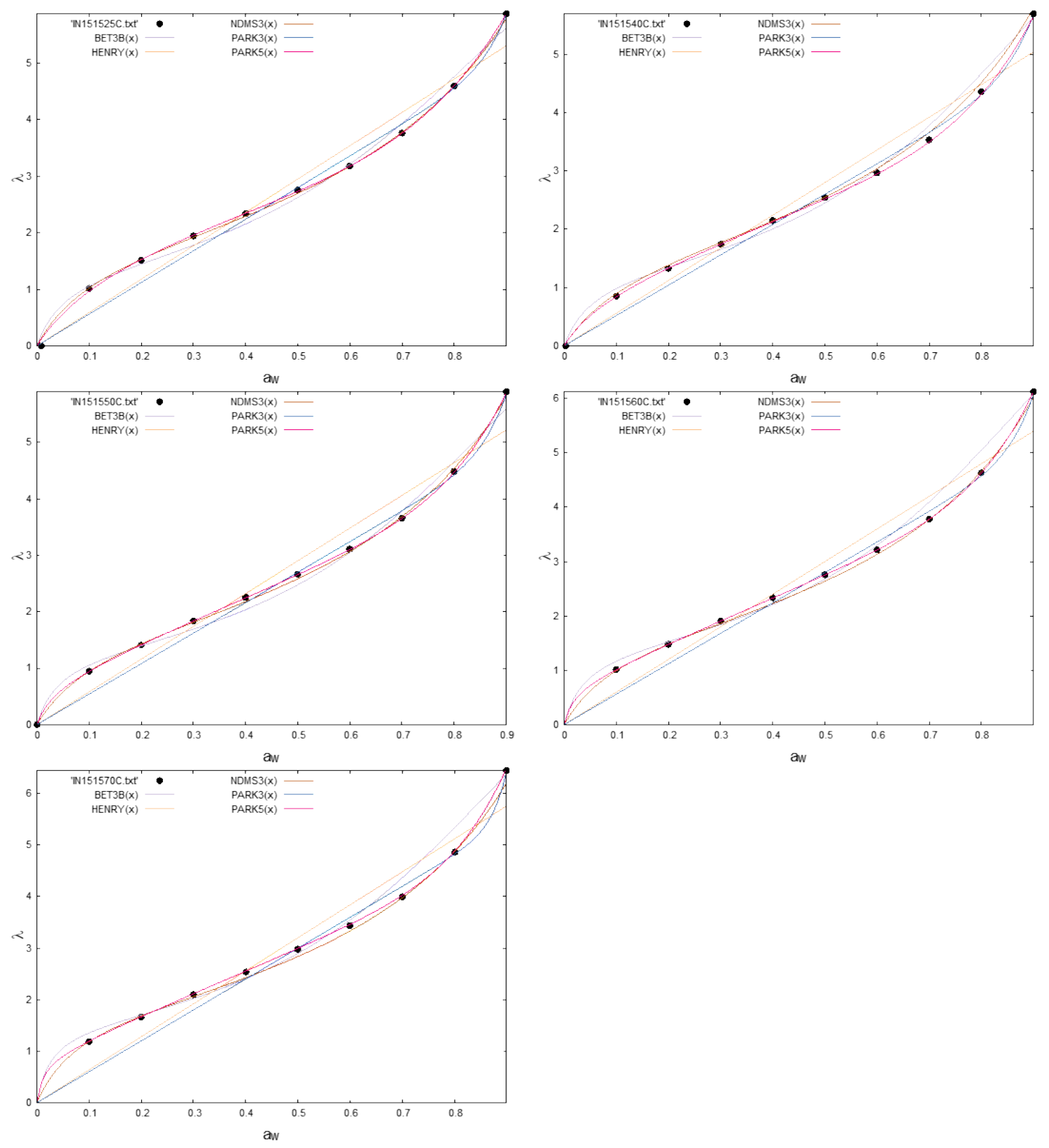

Figure S4. Fits of the sorption data with different models issued from literature for IN1515 at $25^{\circ} \mathrm{C}, 40^{\circ} \mathrm{C}, 50^{\circ} \mathrm{C}, 60^{\circ} \mathrm{C}$ and $70^{\circ} \mathrm{C}$ 


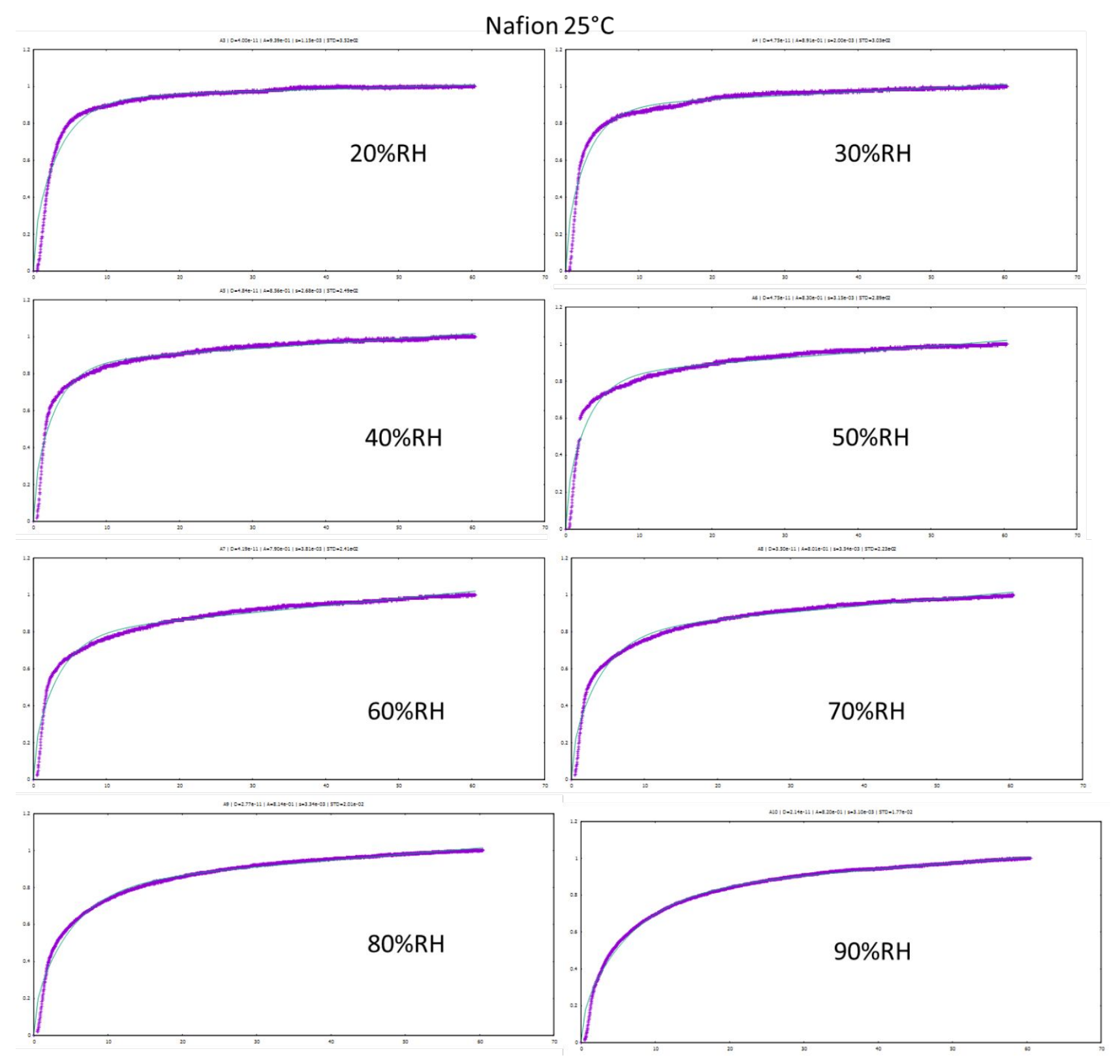

Figure S5: Fits of the experimental data with the equation 5 to determine the diffusion coefficient for Nafion at $25^{\circ} \mathrm{C}$ for humidity steps comprised between $20 \%$ and $90 \% \mathrm{RH}$. 


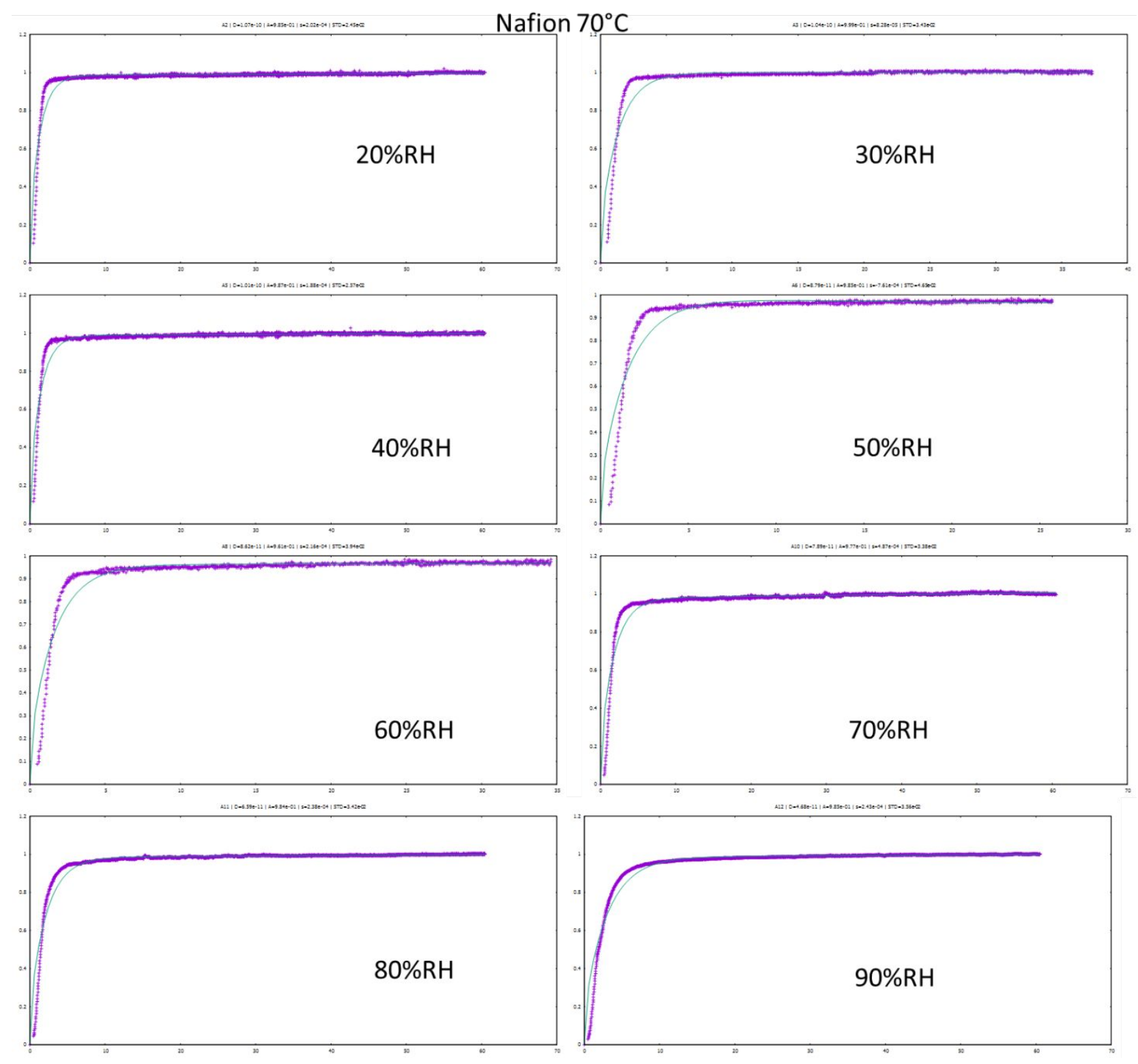

Figure S6: Fits of the experimental data with the equation 5 to determine the diffusion coefficient for Nafion at $70^{\circ} \mathrm{C}$ for humidity steps comprised between $20 \%$ and $90 \% \mathrm{RH}$. 

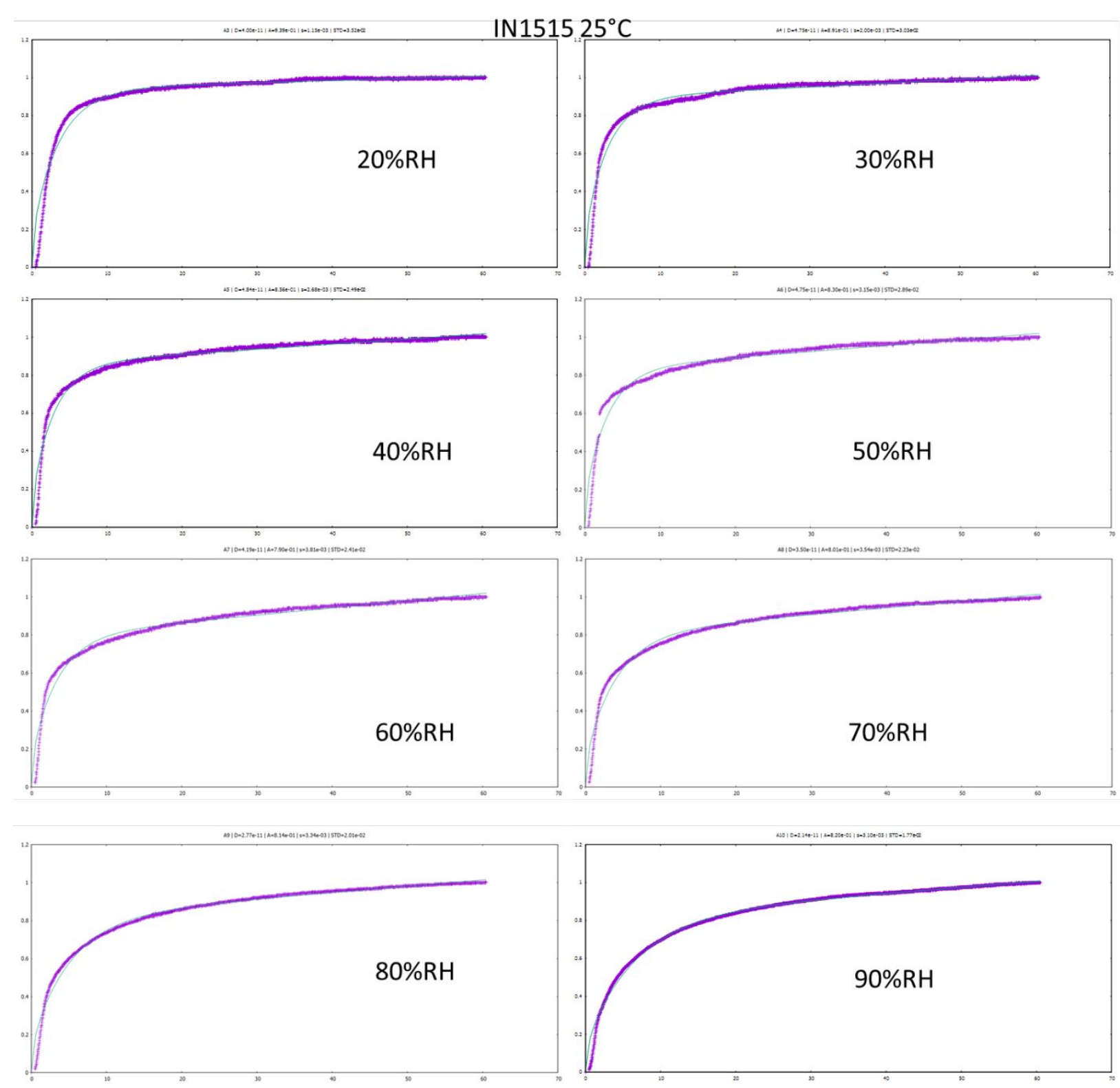

Figure S7: Fits of the experimental data with the equation 5 to determine the diffusion coefficient for IN 1515 at $25^{\circ} \mathrm{C}$ for humidity steps comprised between $20 \%$ and $90 \% \mathrm{RH}$. 


\section{IN1515 $70^{\circ} \mathrm{C}$}
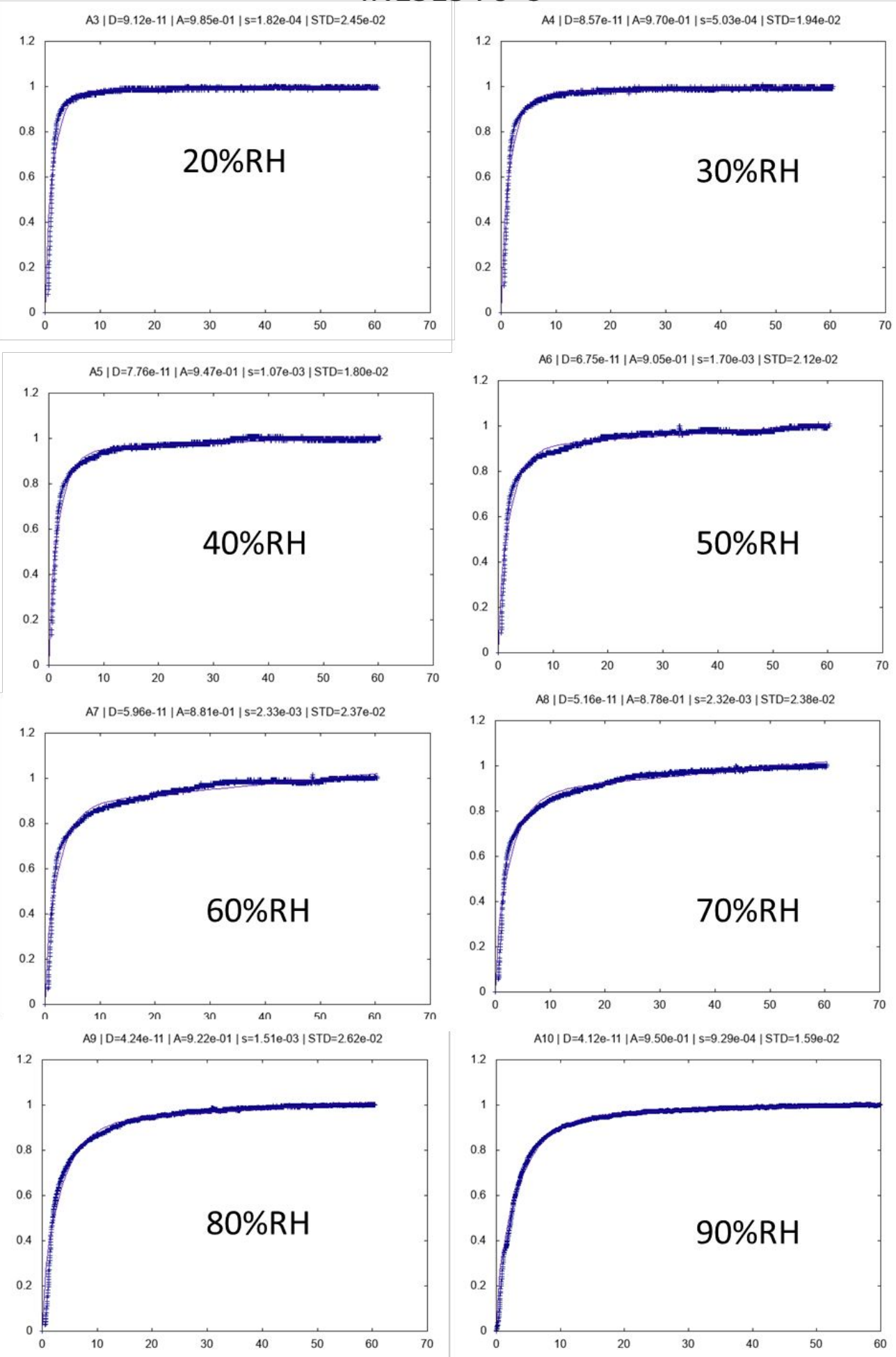

Figure S8: Fits of the experimental data with the equation 5 to determine the diffusion coefficient for IN 1515 at $70^{\circ} \mathrm{C}$ for humidity steps comprised between $20 \%$ and $90 \% \mathrm{RH}$. 

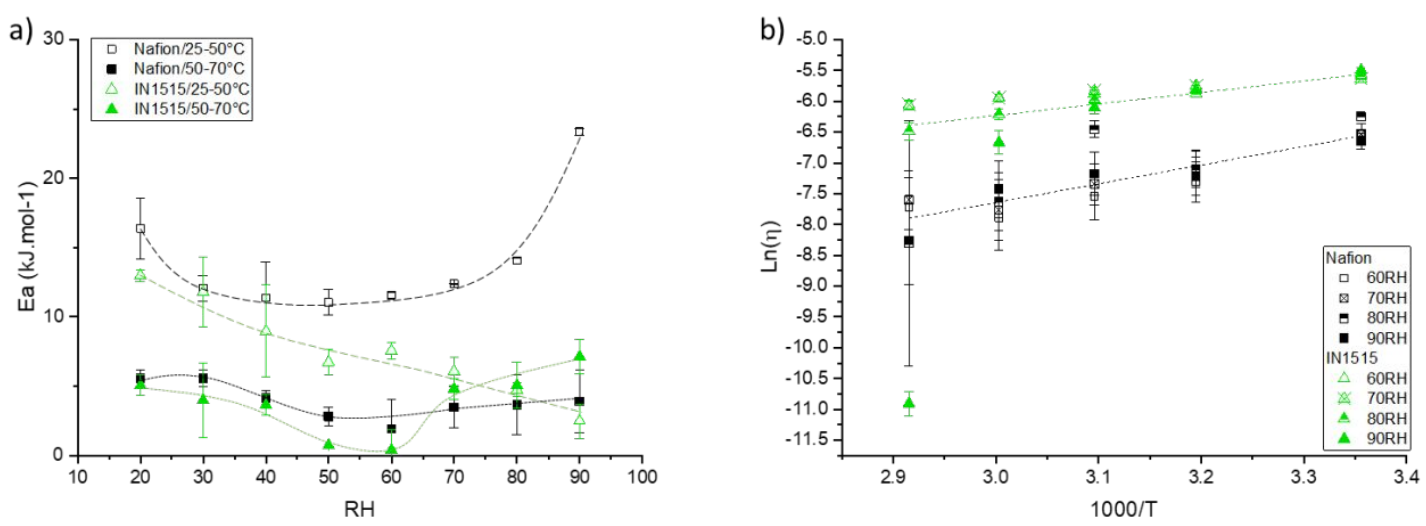

Figure S9. a) Water diffusion activation energy in high temperature range (closed symbols) and in low temperature range (open symbols); b) Temperature dependence of relaxation parameter $\eta$ at variable humidity rate, for Nafion (black) and IN1515 (green)
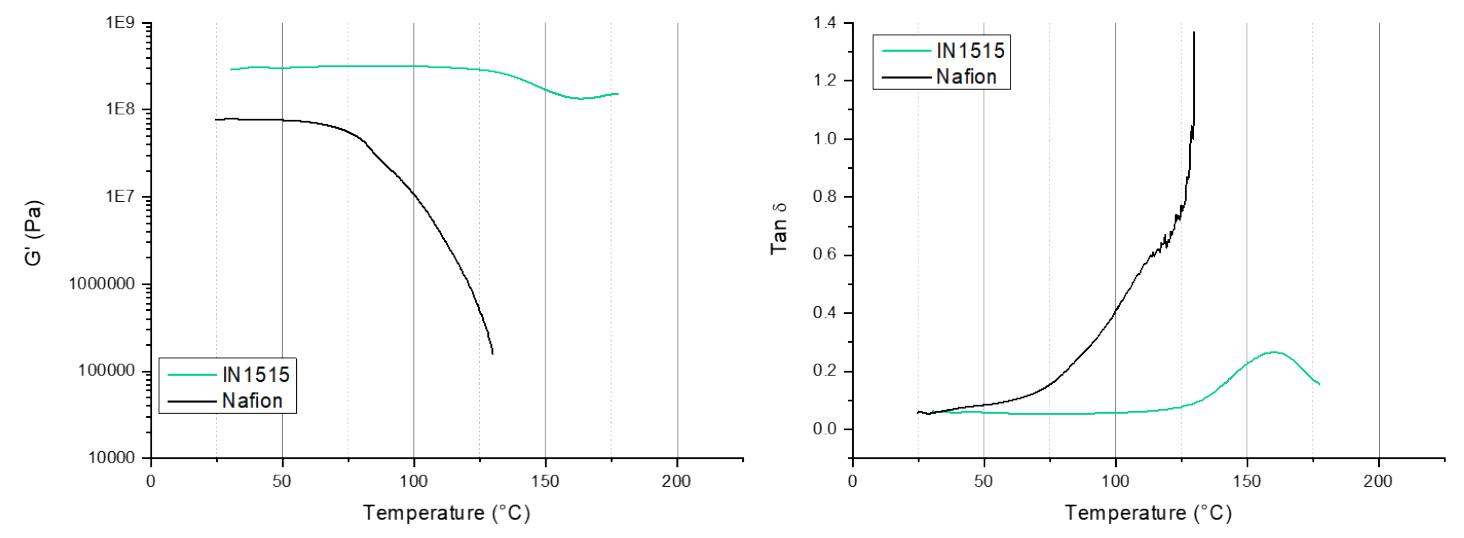

Figure S10. DMA analyses for IN1515 and Nafion ${ }^{\circledR} 117$ in function with temperature: (left) $G$ 'versus temperature, (right) tan delta versus temperature 


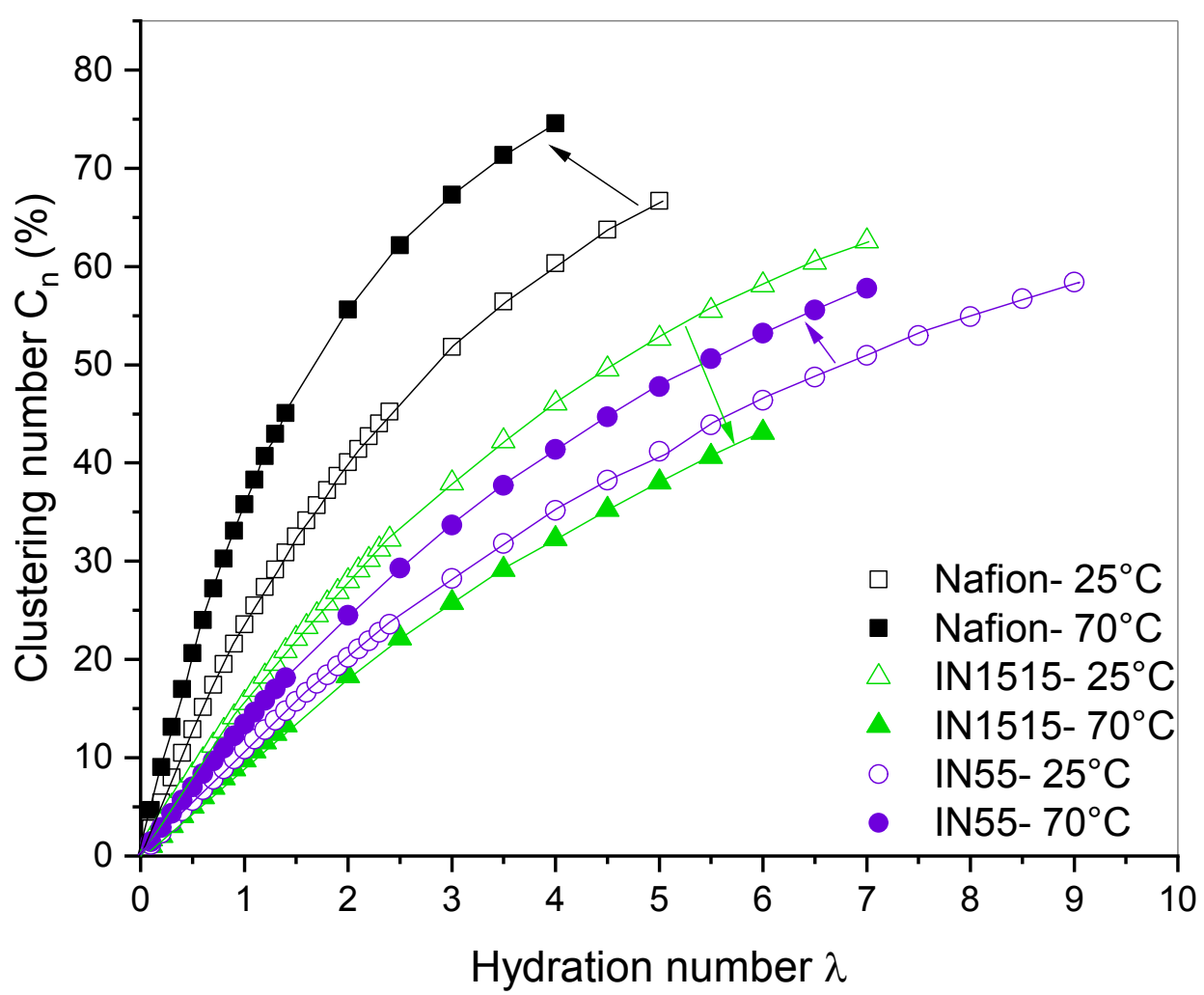

Figure S11. Clustering number $C_{n}$ versus hydration number $\lambda$ in Nafion (Black), in IN1515 (Green) and IN55 (Purple) at $25^{\circ} \mathrm{C}$ (open symbols) and $70^{\circ} \mathrm{C}$ (closed symbols)

References:

(1) Jonquières, A.; Fane, A. Modified BET Models for Modeling Water Vapor Sorption in Hydrophilic Glassy Polymers and Systems Deviating Strongly from Ideality. J. Appl. Polym. Sci. 1998. https://doi.org/10.1002/(sici)1097-4628(19980222)67:8<1415::aidapp7>3.0.co;2-h.

(2) Li, Y.; Nguyen, Q. T.; Buquet, C. L.; Langevin, D.; Legras, M.; Marais, S. Water Sorption in Nafion ${ }^{\circledR}$ Membranes Analyzed with an Improved Dual-Mode Sorption Model-Structure/Property Relationships. J. Memb. Sci. 2013. https://doi.org/10.1016/j.memsci.2013.03.040. 